\title{
A evolução das formas de gentrificação: estratégias comerciais locais e o contexto parisiense
}

\author{
The evolution of gentrification forms: \\ local commercial strategies and the Parisian context
}

Eugênia Dória Viana Cerqueira

\begin{abstract}
Resumo
A literatura atual sobre os processos de gentrificação concentra-se principalmente na análise de áreas impactadas por operações de renovação urbana. 0 presente artigo resulta de uma reflexão qualitativa sobre a evolução das dinâmicas de gentrificação que prioriza o detalhamento de um processo de transformação urbana espontâneo e pontual, espacializado em um quartier parisiense. A pesquisa descrita visa a expandir a tradicional interpretação da gentrificação residencial e focar-se nas lógicas comerciais, que constituem elementos capitais na construção do espaço urbano. Para tanto, desenvolve-se uma abordagem pluridisciplinar que se propõe a identificar os impactos socioespaciais, as tensões traçadas, assim como as representações urbanas decorrentes do processo em questão.
\end{abstract}

Palavras-chave: gentrificação comercial; Paris; geografia do consumo; dinâmicas locais; identidade urbana.

\begin{abstract}
The current literature on the process of gentrification focuses mainly on the analysis of areas that are impacted by urban renewal operations. This paper results from a qualitative reflection on the evolution of the gentrification dynamics and describes a specific and spontaneous transformation process that has taken place in a Parisian quartier. The research presented in this paper aims to expand the traditional interpretation of residential gentrification and focuses on the commercial logics, which constitute key elements in the construction of the urban space. To do so, a multidisciplinary approach is developed in order to identify the socio-spatial impacts, the social tensions, and the urban representations resulting from the above-mentioned process.
\end{abstract}

Keywords: commercial gentrification; Paris; geography of consumption; local dynamics; urban identity. 


\section{Introdução}

As inúmeras mutações que fundamentaram as sociedades urbanas contemporâneas assinalam a evolução de determinados territórios, que se complexificam sobre novos moldes de organização espacial e funcionamento da estrutura urbana. Sob a forma de tecidos urbanos dispersos e fragmentados, a cidade pós-moderna testemunha movimentos simultâneos e paradoxais, em que o espaço, atuando como produto social e meio de controle, materializa a organização social (Mendes, 2011). 0 conceito de gentrificação evidencia, simultaneamente, as dinâmicas de segregação urbana, assim como os desafios de articulação entre transformações urbanas, sociais e estruturação do território. Tal processo, um objeto de discussão familiar às disciplinas de ciências humanas, foi difundido primeiramente nas cidades americanas e europeias e estende-se atualmente às grandes cidades do mundo todo. 0 termo, originalmente explorado por sociólogos, visava a analisar o processo de substituição das classes populares pelas classes superiores em setores desvalorizados das grandes cidades (Bidou-Zachariasen, 2006). No decorrer das últimas décadas, o fenômeno incidiu principalmente sobre diversas áreas centrais urbanas que, frequentemente alvo de políticas de revalorização urbana, se reinventam como espaço de residência, consumo e lazer para as classes superiores. 0 contexto atual assinala ainda a emergência de uma nova definição de gentrificação, que evolui de um processo pontual e característico às áreas centrais a uma estratégia global articulada à reprodução das dinâmicas capitalistas (Mendes, 2011).
A maioria dos estudos realizados no campo em questão aborda o conceito clássico de gentrificação, privilegiando a análise do impacto das renovações e transformações urbanas sobre o local de residência e sobre as experiências dos indivíduos que habitam as áreas em questão. Uma gama de pesquisa distinta orienta-se à exploração qualitativa dos grupos sociais causadores desse fenômeno, os chamados gentrificadores. Entretanto, constata-se que grande parte da literatura referente à gentrificação aborda de maneira superficial a incidência desse processo sobre as estruturas comerciais (Van Criekingen e Fleury, 2006). Sob essa perspectiva, é pertinente assinalar a interlocução entre as atividades de comércio e as dinâmicas urbanas, uma vez que as transformações de tais estruturas traduzem a emergência de uma nova demanda local, articulada à apropriação do mercado pelas classes qualificadas.

Nesse sentido, a análise das estruturas e da paisagem comercial emerge como um elemento capital para a compreensão do tecido urbano. 0 conceito de "nova geografia do comércio", fundamentado sobre a reconfiguração das estruturas de serviço de grande porte, conduz a uma conversão da antiga geografia do comércio à chamada geografia do consumo (Mermet, 2011). Tais dinâmicas se organizam acerca de paradigmas culturais que configuram os novos espaços de consumo e da consequente produção identitária acarretada por esses. Assim, presencia-se a emergência de um campo de estudo geográfico inédito, que se articula progressivamente às temáticas urbanas. Comércio e serviços são inseridos gradativamente nos grandes projetos de operação urbana difundidos mundialmente nas últimas décadas, 
e consequentemente, emergem como objetos fundamentais das análises referentes ao processo de gentrificação.

0 cenário descrito delineia os grandes empreendimentos comerciais e os consumidores, ou gentrificadores, como os principais pontos de ênfase dos recentes estudos. Os novos ensaios esboçados sobre o tema têm como foco principal a articulação entre os shoppings centers implantados em áreas centrais e seus consequentes impactos no tecido comercial urbano. Contudo, Van Criekingen e Fleury (2006) postulam que as análises que consideram o papel das funções ou do capital comercial como atores intrínsecos ao processo de gentrificação permanecem pontuais. Em consequência, as dinâmicas comerciais microescalares e espontâneas restam pouco exploradas na literatura consagrada à gentrificação. Uma vez que o comércio local se encontra dissociado das grandes operações comerciais, a dinâmica que tange a essas atividades se traduz em novos locais de consumo, estratificados em torno de nichos culturais que embasam as experiências e representação dos modos de vida das classes favorecidas, as quais se apropriam gradativamente dos espaços em questão (Bell e Jayne, 2004). Se anteriormente cultura e consumo configuravam duas categorias paradoxais, atualmente observa-se um processo de mercantilização da primeira e seus signos, que adquire um papel progressivo na concepção dos produtos capitalistas (Scott e Leriche, 2005).

Uma das premissas do trabalho de Santos (2002) consiste na redescoberta das práticas cotidianas e da dimensão local, articuladas às facetas e às nuances que delineiam a vivência do espaço urbano, tais como os movimentos sociais e a identidade local. Nesse sentido, questiona-se um processo de gentrificação pontual mais complexo e menos linear que as formas clássicas detalhadas na literatura. Como se dá a gentrificação decorrente de dinâmicas pontuais? Qual seu impacto sobre a estrutura socioeconômica e sobre a organização identitária local? Quais as lógicas intrínsecas às novas formas de gentrificação que ultrapassam a esfera residencial?

0 presente artigo pretende precisamente assinalar os principais resultados alcançados em uma pesquisa desenvolvida no âmbito da gentrificação comercial. Na supramencionada investigação procurou-se apurar algumas pistas orientadoras possibilitando discutir que contornos poderiam assumir os espaços submetidos a dinâmicas intrínsecas de mutação comercial e seus consequentes impactos sobre a construção identitária, assim como as tensões traçadas no espaço urbano. Trata-se de demonstrar como a atividade comercial pode atuar como elemento motor de um processo de gentrificação pontual, não sendo apenas fruto de dinâmicas essencialmente residenciais. Para detalhar a referida temática, aponta-se como objeto de estudo a cidade de Paris, estruturando-se sobre duas dimensões fundamentais. Em um primeiro momento, articula-se a análise à contextualização da temática na escala da capital francesa, que é submetida, em um panorama global aos efeitos da gentrificação residencial, e, pontualmente, à gentrificação comercial. Posteriormente, visa-se a dissecar as mutações do tecido comercial de um setor central da cidade luz fortemente impactado pela gentrificação nas últimas décadas. A escala de análise permite compreender a interlocução entre a evolução dos processos sociais e as dinâmicas urbanas da área em questão, 
através da triagem de artigos e de entrevistas realizadas in loco com a população, precisamente com a categoria de comerciantes. Nesse sentido, recorre-se, por fim, a uma descrição e à análise crítica dos diversos instrumentos políticos e jurídicos implementados pelo poder público no intuito de combater e mitigar o processo descrito. Assim, conjugando o raciocínio metodológico e a investigação realizada, pretende-se expor as principais conclusões tecidas a partir da articulação de elementos proposta pela pesquisa.

\section{A cidade de Paris: um panorama global de gentrificação}

A gentrificação emerge como fruto de diversos processos recentes como a metropolização e a mundialização, adquirindo um papel ímpar na produção de mais-valia do mercado imobiliário e na estruturação econômica das grandes aglomerações (Smith, 1996). Paris se insere no contexto das diversas metrópoles que, no decorrer das últimas décadas, testemunharam a difusão gradual da gentrificação em suas áreas centrais. Ainda que tal processo tenha se propagado de maneira tardia com relação a outras métropoles como Londres e Nova York, a capital francesa acolhe o desenvolvimento da gentrificação, impulsionado pela crescente desindustrialização, assim como pelo aumento dos preços imobiliários. A partir dos anos 1960 , os quartiers centrais do norte parisiense se transformam progressivamente, e as áreas situadas ao sul são objeto de diversas políticas públicas de reabilitação que corroboram a atração das classes qualificadas (Clerval e Fleury, 2009). Nos anos 1990 catalisa-se a dilatação da gentrificação parisiense, que passa a permear a cidade luz em uma escala global. São principalmente os atores privados que contribuem com a dinâmica descrita, sob formas de investimento na reabilitação e revalorização da habitação popular degradada. Se em 1982 as classes populares representavam $42 \%$ dos parisienses, em 2008 essas constituem 27\% da população total da cidade luz (Clerval, 2013).

A gentrificação referente à ocupação residencial constituiu e ainda constitui um objeto de análise recorrente, tendo sido identificada e assinalada na cidade de Paris por inúmeras pesquisas. Clerval (2010) desenvolve um estudo precisamente detalhado, cartografando o caráter espacial, bem como a temporalidade do movimento de valorização residencial parisiense. Nesse sentido, identifica-se claramente um movimento centrífugo que caracteriza a permutação das classes populares, que ultrapassam as fronteiras administrativas dos 20 arrondissements do núcleo da métropole. ${ }^{1}$ Os espaços periféricos englobam, dessa maneira, um alto percentual de habitantes provenientes das áreas centrais da capital e as zonas norte e leste da capital acolhem progressivamente uma população qualificada. Assim, o processo supracitado embasa-se em temporalidades distintas, uma vez que coexistem espaços de gentrificação consumada e gentrificação em processo de emergência. 
Figura 1 - A evolução do processo de gentrificação em Paris

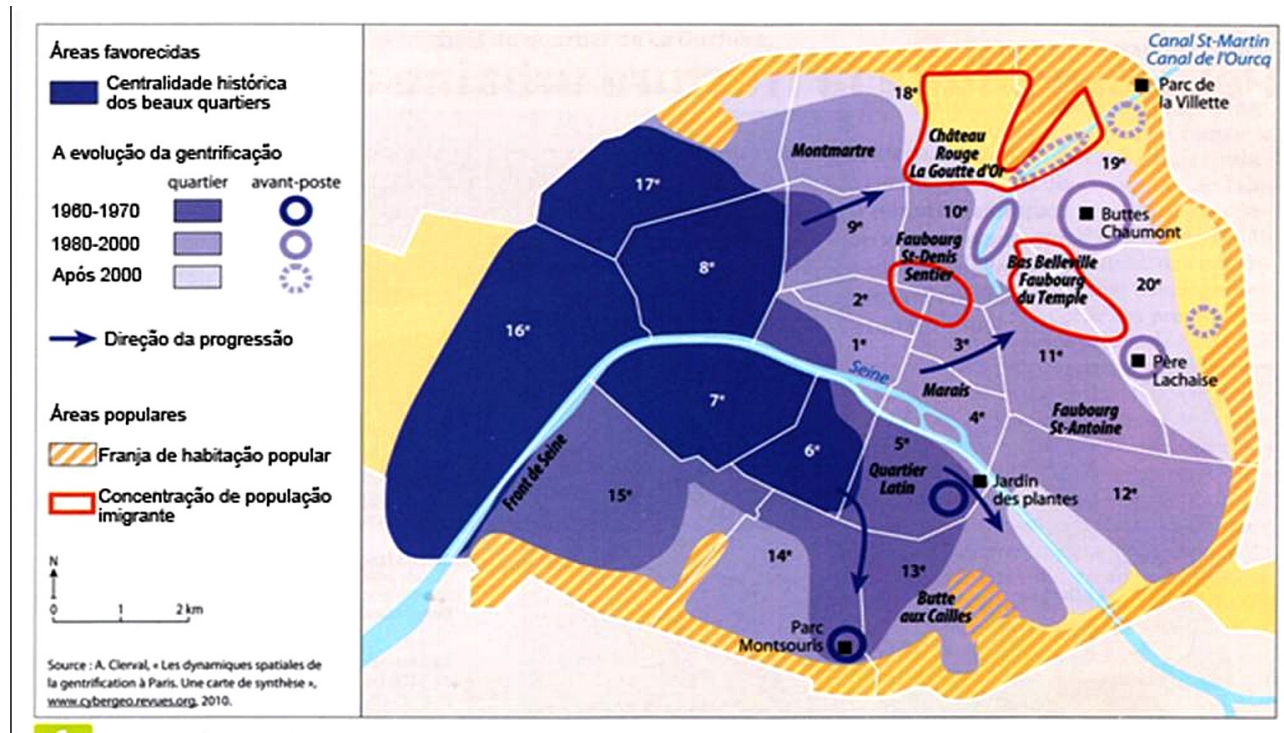

1 La gentrification de Paris

Fonte: Clerval (2010).

Sob essa ótica, a cidade luz testemunhou igualmente a gentrificação de seus espaços comerciais. Desde a substituição das galerias de arte pelo comércio de luxo no Saint-Germain, passando pela gradual apropriação do comércio homossexual no Marais, até a emergência de bares especializados em Faubourg Saint-Antoine. Entretanto, poucas pesquisas permitem esboçar a organização espacial do processo de gentrificação comercial na capital francesa. Se alguns estudos apontam de maneira dispersa e microescalar o fenômeno, observa-se a ausência de pesquisas que permitam identificar e cartografar o panorama global da gentrificação do aparelho comercial parisiense, como traçado em relação ao contexto residencial.
0 contexto comercial de Paris é preciso e particular: beneficiando-se de polos cuja atratividade ultrapassa as fronteiras administrativas da cidade luz e se difunde a uma escala internacional, trata-se de uma aglomeração urbana cujo maior desafio não consiste na concepção de uma heterogeneidade comercial, mas sim em sua manutenção. 0 contexto contemporâneo parisiense abrange um forte dinamismo dos grandes espaços de comércio alimentar industrializados em detrimento dos comércios alimentares artesanais e dos pequenos armazéns tradicionais. Aponta-se igualmente uma progressão de todas as atividades promovendo produtos articulados ao corpo e à saúde. Um estudo temático realizado pelo Atelier Parisien 
d'Urbanisme (Apur) em 2011 sugere a ascensão de uma categoria de atividades interpretada como "bem-estar", que dialogam não somente com os setores de saúde e beleza, mas englobam também objetos de consumo diário, como determinados produtos alimentares.

Assim, a emergência de centralidades de lazer e de consumo progressivamente dispersas e distantes do centro consiste em um fenômeno mundial e paralelo à gentrificação, em que os paradigmas de uma sociedade hipermóvel processam a extensão virtual da centralidade urbana espacial. Nesse sentido, aqueles que se apropriam dos espaços em questão são inscritos em um circuito de dinâmicas urbanas socioculturais, ainda que tais centralidades não correspondam efetivamente ao núcleo espacial da cidade. Mesmo que o centro aja como uma âncora importante do cenário de manifestações, enuncia-se a progressiva dilatação dos movimentos culturais em direção aos espaços periféricos, contribuindo com a lapidação de novas centralidades de cultura (Pouessel, 2005). Essas processam uma mutação da frequentação das áreas em questão, e uma consequente valorização do espaço urbano que atrai progressivamente os gentrificadores.

Clerval (2008) aponta que o paradigma traçado pelas dinâmicas de gentrificação residencial parisienses tende a se reproduzir com relação às novas centralidades de lazer e de comércio. Dessa maneira, verifica-se uma extensão centrífuga do processo, que culmina nas áreas periféricas da cidade. Nas últimas duas décadas, a saturação da gentrificação em áreas centrais impulsionou a dilatação do processo em direção às franjas urbanas, através da criação pontual de corredores culturais e de consumo. Entretanto, contrariamente à gentrificação residencial, a valorização do comércio local não se processa de maneira linear, e, sim, de forma difusa e esparsa ao longo da cidade, em vias que apresentam uma densidade de serviços importante. Clerval (2008) postula ainda que a gentrificação comercial e de lazer, que abarca progressivamente as áreas norte e leste da capital francesa, contribui a mitigar a oposição histórica entre o norte e o sul parisiense, 0 primeiro considerado como palco da atividade industrial e o último valorizado como centralidade cultural.

A lógica explicitada corrobora a hipótese traçada por Lipovetsky (2006), que evoca que a sociedade de hiper-consumo remodela não somente os espaços de comércio, mas também reestrutura o valor do espaço urbano. Se a cidade industrial era anteriormente concebida através de parâmetros de produção, o contexto pós-industrial idealiza o consumo e o lazer. Assim, o espaço urbano tende a se reconfigurar a partir de valores como ambiência e espetáculo, sob a forma de cidades recreativas que acolhem uma pluralidade de equipamentos como praias urbanas, boutiques de moda, galerias de arte.

Ainda que o processo de gentrificação de atividades e serviços contemple paradoxalmente efeitos de lógica positiva, como a difusão do acesso aos corredores culturais e de comércio, esse também contribui com a ratificação de diversas tensões sociais e urbanas. Sob essa perspectiva, a parte subsequente do presente estudo propõe identificar a evolução gradual do processo de gentrificação comercial de caráter espontâneo, que se opõe àquela decorrente das grandes operações de inovação urbana. A transformação das atividades em um nível local introduz profundas alterações no tecido social e produz uma apropriação reticular do 
espaço urbano. Visa-se, então, a compreender como as lógicas locais corroboram a substituição das atividades de caráter popular e as problemáticas decorrentes desse cenário.

\section{SoPi: traços de gentrificação em um típico quartier parisiense?}

0 perímetro assinalado pelo presente estudo se inscreve no nono arrondissement, situado na região norte de Paris e adjacente à área central da cidade. 0 setor contempla uma posição intermediária, limítrofe, ao mesmo tempo, a espaços centrais favorecidos e a áreas caracterizadas pela ocupação popular. Se por um lado, a região bordeia o setor Haussman-Opéra, um dos principais polos comerciais da Europa, de outro, traça fronteira com uma área altamente ocupada por uma população imigrante. 0 contexto predito corrobora a hipótese traçada por Van Crienkingen et al. (2006), que enuncia que diversos espaços intermediários são atualmente na capital parisiense alvo de processos de gentrificação. Sob essa ótica, trata-se de um setor recentemente impactado pelas dinâmicas de gentrificação residencial e comercial, que se destacam gradativamente no tecido e nas dinâmicas urbanas. A região assinalada, que engloba a área situada ao sul do quartier de Pigalle e ao norte de Notre-Dame de Lorette, adquiriu recentemente a denominação de SoPi (contração referente ao termo South Pigalle), consagrada pelos veículos midiáticos. Esses últimos ajudam a promover a nova imagem gentrificada da região, descrevendo sua ambiência coole trendy, decorrente da instalação de novas lojas orgânicas, bares de coquetel e lojas-conceito.

A zona situada ao sul do setor engloba uma oferta concentrada de escritórios, a segunda da capital francesa. Os demais pontos de SoPi inscrevem uma oferta conjugada de ocupação residencial e comercial. A urbanização do setor em questão deu-se em torno do ano de 1825 , no momento em que especuladores imobiliários adquirem em massa as propriedades da região. A ambiência rural dominante é rapidamente substituída por uma paisagem urbana e heterogênea, composta concomitantemente por edificações luxuosas e populares. A proximidade da Gare Saint-Lazare atrai de maneira significativa as atividades comerciais, que se aglutinam no setor. Assim, a região abarca uma população heterogênea composta pela interlocução entre burgueses e classes populares, inscritos em um contexto denso de edificações centenárias e uma animação constante. A heterogeneidade descrita conduz em sua origem à instalação de uma população artística e boêmia, sob influência histórica do quartier adjacente, Montmartre. Assim, a originalidade desse território é principalmente sua atuação como domínio de interlocução entre diversas zonas de interferência (Soulie, 1954). Entretanto, se o setor conserva atualmente sua autenticidade romântica e arquitetural, suas dinâmicas socioespaciais são objeto de inúmeras metamorfoses nos últimos anos.

De 1990 a 2009, observa-se igualmente uma mutação populacional no setor em questão. Tais movimentos concernem principalmente a natureza das categorias socioprofissionais recém-instaladas, configurando um panorama de aumento considerável da população qualificada. A implantação dessa se dá de maneira 
Figura 2 - Delimitação do perímetro de estudo - o setor de SoPi

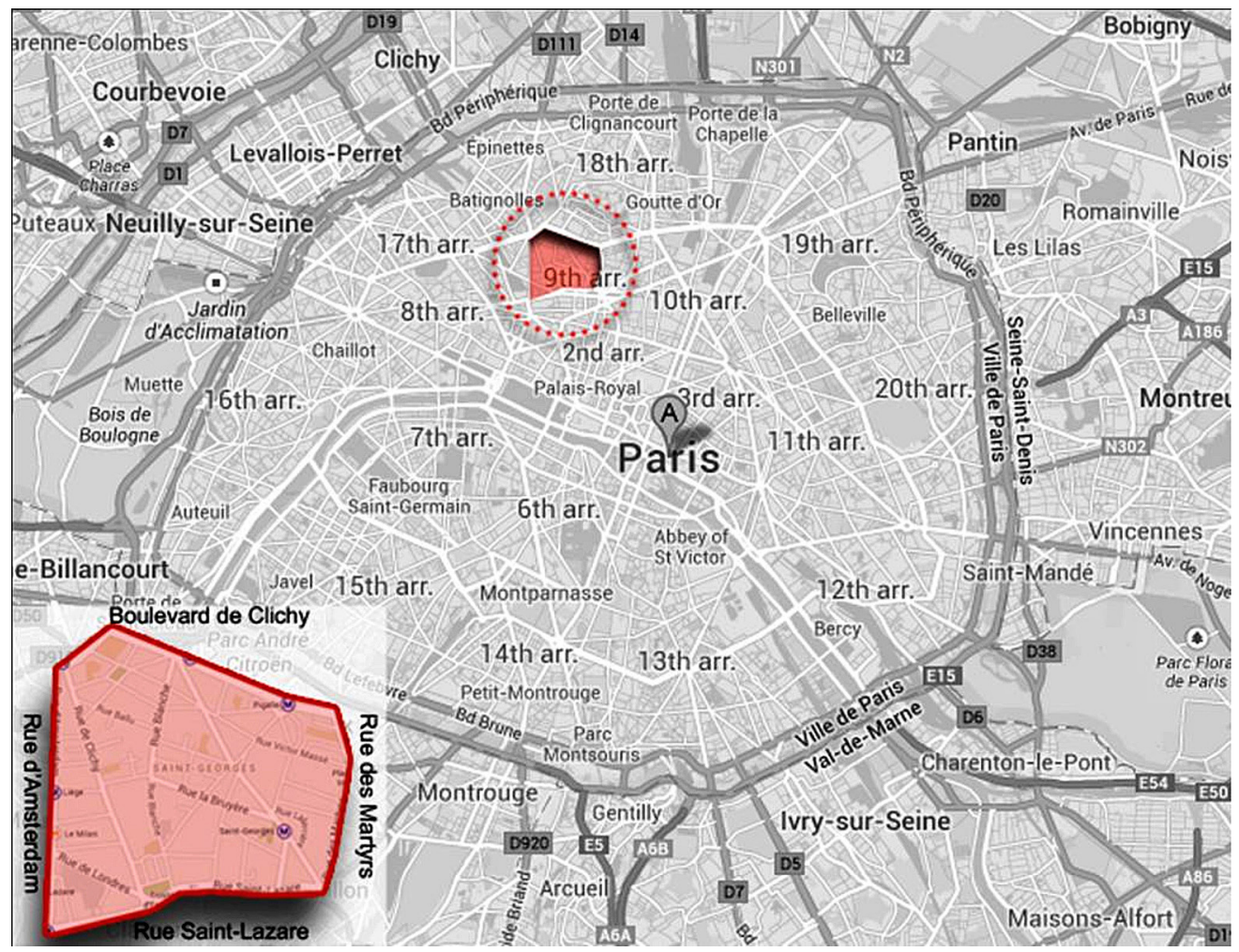

Fonte: Google Maps, manipulado por Eugênia Viana Cerqueira.

mais acentuada principalmente a partir dos anos 2000. Consequentemente, o percentual de outras categorias sociais populares, tais como os operários e empregados, decresce significativamente. A dinâmica descrita, reflete de maneira ilustrativa o processo de gentrificação observado em uma escala global na aglomeração urbana parisiense. 0 cenário desenhado incide igualmente sobre as tarifas imobiliárias, que aumentam vertiginosamente na capital de maneira generalizada. Assim, os agentes do setor imobiliário utilizam-se da denominação Village des Martyrs, referente à icônica Rue des Martyrs, para promoção da área apontada como ponto emergente de atração de uma população profissionalmente qualificada ( New York Times).

Os preços aumentam de maneira constante há dez anos, e de maneira um pouco mais acelerada durante os cinco últimos anos [..] As pessoas que compram ou alugam aqui são principalmente os jovens solteiros e jovens famílias de classe superior, com um ou dois filhos. Aqui é uma região agradável, típica de Paris, ideal pra criar os filhos. (T. L.,42 anos, corretora imobiliária) 
Figura 3 - Evolução da composição socioprofissional do setor de SoPi ${ }^{2}$



Fonte: Censo da população 1990, 1999 e 2009, INSEE. Dados manipulados.

Assim, a população emergente no setor é frequentemente caracterizada e definida pelos veículos midiáticos como bobo, contração derivada do termo inglês bourgeois-bohemian, cunhado por Brooks através da obra Bobos in paradise (2000). 0 vocábulo refere-se a uma classe qualificada, resultante da fusão entre os grupos de burgueses e boêmios, ${ }^{3}$ que cultiva modos de vida diversificados e frequentemente articulados ao consumo de universos, como a comunicação, novas tecnologias, e à cultura. Nesse sentido, a metamorfose testemunhada pela população local incide diretamente sobre o tecido urbano comercial do setor.

\section{A gentrificação e o comércio local}

SoPi é composto por um tecido comercial denso, em que coexistem atividades comerciais especializadas e comércios locais. As principais vias comerciais do perímetro analisado são a Rue des Martyrs, Boulevard Clichy e Rue Pierre Fontaine, que abarcam um número significativo de comércios de atratividade local. Através de análises detalhadas verificou-se a evolução do aparato comercial e uma consequente mutação da frequência socioeconômica do setor. $A$ denominada gentrificação comercial induz aos 
mesmos tipos de prática que a clássica gentrificação residencial, ou seja, a substituição de camadas populares da população. Entretanto, a primeira não abarca necessariamente a população que habita um determinado território, e, sim, os indivíduos que o frequentam. Nesse sentido, a gentrificação comercial apresenta particularmente uma temporalidade que difere daquela da gentrificação residencial.

Bidou-Zachariasen (2006) aponta que a articulação entre os diversos tipos de gentrificação variam de acordo com o cenário econômico e social em que se inscrevem. Como explicitado por Chabrol (2011), que disseca o contexto da Goutte d'Or no norte parisiense, as gentrificações comercial e residencial encontram-se dissociadas e inscrevem-se em lógicas e temporalidades distintas. No cenário predito, a gentrificação residencial não acarreta necessariamente a valorização da atividade comercial, que conhece a manutenção do comércio popular imigrante da região. Contudo, ainda que apontados como fenômenos distintos, em determinados contextos as gentrificações comercial e residencial seriam articuladas, sobrepostas, e, frequentemente, a primeira seria intensificada em consonância com as transformações da população residente.

0 contexto supracitado é esboçado de forma evidente no perímetro estudado. Historicamente, a região foi palco de diversas casas noturnas (dentre as quais o icônico Moulin Rouge) e posteriormente passou a abrigar atividades relacionadas ao consumo sexual, como sex-shops e os chamados bar à hotesse. ${ }^{4}$ Entretanto, como consequência direta das mutações comerciais presenciadas, advindas da evolução da clientela do setor, de 2007 a 2011 as atividades de caráter popular decrescem consideravelmente na região. 0 número de sex-shops diminui por volta de $28 \%$, em detrimento da implantação de novos estabelecimentos especializados, principalmente em instrumentos musicais (Semaest, 2011). A presença de áreas turísticas, como o quartier Montmartre, ${ }^{5}$ nas adjacências incita igualmente o desenvolvimento de atividades destinadas aos novos visitantes.

A escassez de espaços públicos estruturantes no perímetro induz à substituição desses pelas vias de circulação, que reconstituem sua função original de espaço de sociabilidade e animação. A Rue des Martyrs, já mencionada como uma das principais vias comerciais do setor, presenciou diversas transformações recentes que refletem o panorama global das evoluções constatadas. Tal corredor demonstra de uma maneira particular e intensificada o fenômeno generalizado de gentrificação e transformações urbanas e sociais que incidem no quartier. A via, tradicionalmente comercial, atua até hoje como um dos pontos de referência da região no que concerne não somente a oferta de serviços, mas também a construção de uma identidade popular local: entre mercados, floristas e peixeiros, a Rue des Martyrs concentra atualmente $31 \%$ dos comércios alimentares do setor (Semaest, 2011).

A partir dos anos 1990, o setor, em especial a via supracitada, presencia uma transformação de sua estrutura comercial, acolhendo a instalação de novos tipos de comércio especializado, principalmente de caráter alimentar, que são denominados concept stores ou magasins concept. A premissa de tais estruturas concentra-se na promoção de um universo temático, como o luxo e o design, priorizando um estilo de vida em detrimento do produto fornecido. 
De cupcakes a automóveis, os magasins concepts têm o objetivo de proporcionar ao cliente experiências que ultrapassem o consumo propriamente dito, incitando frequentemente o caráter multidimensional e sinestésico das interações entre cliente e espaço de venda. Nesse sentido, a dimensão estética dos espaços comerciais atuaria como um dos principais elementos dessa equação, assim como 0 aspecto sensorial e corporal da experiência de consumo (Lipovetsky, 2006).
Inauguramos a loja no início desse ano (2012) [...] Foi quando tivemos a ideia de abrir um comércio especializados no choux à la crème, que nós fabricamos de maneira artesanal [...] foi um risco com certeza, mas tem dado certo [...] E preferimos abrir por aqui mesmo, nós amamos essa nova. hum.. ambiência do bairro. Moro aqui há muitos anos e no final decidimos ficar aqui por causa da afinidade com a região. A imagem que ela transmite atualmente é muito favorável para os negócios e atrai uma boa clientela. (L. R, 26 anos, comerciante)

Figura 4 - Magasin concept na Rue des Martyrs

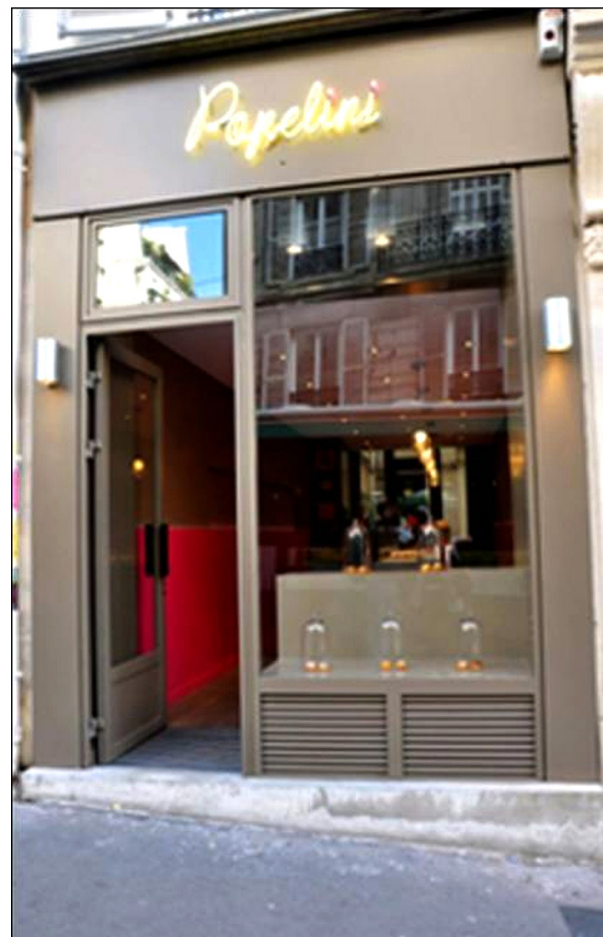

Fonte: Foto de Eugênia Viana Cerqueira (2012). 
0 discurso em questão remete à busca, por parte dos novos empreendedores, da construção de uma nova identidade do espaço urbano. Assim, as categorias de empresários emergentes, que se apropriam da pressuposta zona gentrificada, comercializam novas formas de pensar e experienciar a cultura. Dessa maneira, a emergência de magasins concept na região de SoPi estaria diretamente relacionada à transformação social observada, uma vez que as práticas de consumo seriam apontadas por inúmeros estudos sociológicos como um parâmetro ímpar de diferenciação social (Mermet, 2011).

No caso do objeto de análise parisiense os estabelecimentos descritos teriam como clientela-alvo a nova população qualificada recém-instalada na área e nos setores adjacentes. Entretanto, o tipo de comércio desenvolvido se distingue das grandes cadeias de luxo, uma vez que é articulado a outros modos de consumo, que, interligados à gentrificação comercial, remetem à afirmação da individualidade do consumidor (Van Crienkingen et al., 2006). Sob essa perspectiva, pode-se afirmar que a concentração territorial de uma área de atividade suscita a atração de demais iniciativas comerciais de natureza similar e potencializa dinâmicas decorrentes da esfera de gentrificação comercial (Dias, 2011). Utiliza-se, então, de estratégias tais que as denominadas economias de aglomeração, que pressupõem o benefício de uma determinada atividade pela proximidade a outras de mesma natureza. Tais atividades estruturam-se de forma a sustentar um equilíbrio concorrencial interno e um ganho de produtividade, no caso derivado da construção de uma identidade comercial local.

Se por um lado, a instalação dos estabelecimentos mais antigos parece ligada à proximidade do local de residência dos comerciantes, em sua maioria habitantes do setor, ou à disponibilidade de espaços livres, a implantação das novas atividades comerciais é precisamente proposital. A concentração de atividades destinadas a uma clientela qualificada estimula um tipo de negócio que se embasa sobre a especificidade do público que a zona atrai, composto essencialmente por indivíduos com um elevado poder aquisitivo. Ainda que o perímetro delimitado não faça objeto de divulgações midiáticas abundantes, os veículos de comunicação utilizam-se de adjetivos como "íntimo" e "convivial" para descrever o setor, visando a promover sua ambiência tradicional. Em consequência, a mídia constrói imagens territoriais nos quais segmentos sociais específicos identificam pontos de referência, possibilitando a construção de uma nova identidade espacial por intermédio de um conjunto de aspectos simbólicos. Dessa maneira, um setor cuja atividade comercial se restringia anteriormente a uma atratividade essencialmente local, presencia uma dilatação de sua área de influência, que repercute sobre diversos setores parisienses.

Com certeza os comércios aqui têm evoluído muito [...] bom, a mim não me atrapalha, as coisas mudam, temos que aprender a evoluir de acordo com o tempo. Se as coisas estão mudando então temos que achar um jeito de nos adaptarmos para conseguirmos sobreviver, não é mesmo? (I. B, 60 anos, padeira) 
Sob essa perspectiva, testemunha-se a evolução de uma identidade local construída e lapidada durante mais de um século, que contempla gradualmente um processo de mutação e de fragmentação. Mendes (2011) frisa que a identidade no panorama urbano contemporâneo desloca as estruturas da sociedade moderna, de maneira a abolir um cenário de ancoragem dos indivíduos em um contexto social único. Se na cidade industrial as práticas e modos de consumo se espacializavam de maneira homogênea, o sujeito contemporâneo, pertencendo simultaneamente a categorias plurais, contribui com a concepção de uma identidade territorial diversa e efêmera. Assim, os próprios gentrificadores são cada vez menos identificáveis como uma categoria social uníssona, mas, sim, como um grupo diversificado e associado a uma multiplicidade de práticas e padrões culturais que se complexificam progressivamente, tornando-se mais individuais e consequentemente menos suscetíveis a tipologias qualificativas.

0 contexto descrito corrobora igualmente 0 aumento da atividade turística no setor, atua como local de atração aos visitantes de classes elevadas. Paradoxalmente, tais turistas são induzidos a descobrir um bairro típico parisiense, caracterizado por sua antiga ambiência boêmia e popular. Contrariamente, a nova clientela em questão tende a frequentar os novos bares e magasins concepts em detrimento dos antigos comércios de caráter popular. Nesse sentido, trata-se de uma espécie de reinterpretação dos usos tradicionais da região como ferramenta de atração e como estratégia que vise a moldar uma nova imagem correspondente aos novos consumidores. Entretanto, tais dinâmicas contribuem para a exclusão das categorias socioeconômicas que se apropriavam do espaço anteriormente. Um exemplo revelador é a evolução testemunhada pela casa noturna Chez Moune, que anteriormente destinada a um público homossexual popular, abriga atualmente uma clientela composta principalmente por jovens qualificados.

Sob essa ótica, verifica-se uma articulação delicada entre as transformações sociais e as mutações da estrutura urbana. Nesse contexto, traçam-se tensões sociais que emergem entre os novos comerciantes e aqueles implantados anteriormente. A instalação de novas atividades comerciais tange também aos antigos proprietários, que se sentem ameaçados. Dessa maneira, as atividades comerciais que não se adaptam ao novo mercado, ao qual são inscritas involuntariamente, não conseguem se manter na região.

Estamos aqui há quinze anos [...] É um fato que os preços aumentaram muito e não param de aumentar. Isso faz com que as pessoas que não têm acesso aos preços dos aluguéis tenham que sair da região. Sinceramente, mesmo para a gente é cada vez mais dificil manter a nossa loja aqui [...] Moramos aqui há bastante tempo, mas se eu tivesse escolha atualmente eu não teria escolhido abrir um comércio aqui nessa rua. (J. F, 55 anos, florista)

Ainda que se verifique um contexto dominante de substituição gradual de novos tipos de atividade comercial, é possível encontrar no setor determinados estabelecimentos comerciais de caráter popular e tradicional, que perduram durante os anos. Entretanto, diante da progressão gradual dos preços imobiliários, a manutenção de tais comerciantes impõe-se como um desafio no contexto atual. 
[...] Nós somos turcos, eu e minha mulher mudamos pra cá nos anos 70 [...] Os preços são muito altos hoje em dia, é uma pena, porque é um bom bairro. A gente morava aqui antigamente, mas depois tivemos que mudar, o aluguel, tudo, estava muito caro! Felizmente ainda conseguimos manter a nossa loja aqui, mas não sei mais por quanto tempo vai durar [...] (P. K, 63 anos, alfaiate)

Sob essa perspectiva, a imagem e a representação do espaço urbano teriam uma influência ímpar sobre os fenômenos desenvolvidos. 0 cenário descrito anteriormente conduziu à implementação de comércios de cadeia de vestimentas, cuja presença se amplifica gradativamente em SoPi. Esse contexto remete à progressão das cadeias de comércio, ou seja, todo comércio se regrupando com outros sob uma vitrine comum, na malha comercial parisiense (Apur, 2011). Tais atividades interpretam os espaços potencialmente atrativos como uma vitrine urbana, ou seja, um meio de reforçar sua própria imagem com relação a uma clientela em potencial. 0 contexto descrito consolida um cenário em cujo desenvolvimento do processo de gentrificação e seus efeitos socioespaciais são progressivamente identificáveis. Em consequência, observa-se a emergência não só de análises críticas urbanas referentes ao setor em questão, mas também de políticas públicas cujas premissas advogam a favor da manutenção do comércio tradicional e a mitigação decorrente das dinâmicas de gentrificação, que serão discutidas na sequência.

\section{Políticas públicas paradoxais: incentivo ou combate da gentrificação?}

Se inicialmente a gentrificação era alavancada pelos próprios gentrificadores em escalas pontuais, a partir dos anos 1990 o processo é corroborado pela intervenção das municipalidades, em parceria com a iniciativa privada, que promovem estratégias qualificadas como de regeneração urbana. Já a partir dos anos 2000, o poder público parisiense processa uma participação mais ativa no que concerne à lapidação do espaço urbano, tendo como objetivos principais a revalorização e a patrimonialização. Clerval et al. (2009) advogam que a geografia das políticas públicas da cidade luz revela a implicação progressiva dos atores políticos em consonância com a difusão da gentrificação. As ações políticas recentes embasam-se na utilização de instrumentos jurídicos, como o direito de preempção, ${ }^{6}$ visando a reabilitar as residências vetustas e erradicar a habitação diagnosticada como insalubre. Nesse sentido, as políticas governamentais contribuem com a fundamentação de paisagens urbanas que são idealmente consumidas pelas classes superiores (Smith, 2003) e as renovações catalisadas pelo poder público tendem não somente a dificultar 0 acesso das classes populares à habitação, mas também a descaracterizar as representações simbólicas desenvolvidas por essas últimas no espaço urbano. Para Mendes (2011) o poder público preconiza a dominação 
das classes superiores e interesses do capital por intermédio de intervenções de renovação urbana que traduzem uma orientação que permite beneficiar os promotores imobiliários em função de um processo de segregação seletiva. Assim, os recentes produtos imobiliários da gestão urbana permitem a promoção da lógica do controle social favorável à reprodução do capital e às classes dominantes.

Em interlocução frequente com o processo de gentrificação encontram-se políticas que incitam o desenvolvimento das atividades culturais no espaço urbano. Diversas tentativas de emular uma ambiência similar àquela do SoHo novaiorquino emergem nas mais diversas capitais. Se o desenvolvimento cultural é muitas vezes concertado pela iniciativa privada, as políticas públicas da prefeitura de Paris abarcam também uma instância de desenvolvimento cultural, pela concepção de novos equipamentos e da transformação de franjas industriais em locais de consumo e produção cultural (Clerval et al., 2009). Concomitantemente os atores políticos elaboram paradigmas de incentivo às manifestações culturais e à apropriação do espaço público que são intrumentalizados no intuito de construir uma nova identidade desses espaços e que contribuem consequentemente com a gentrificação das áreas em questão.

Se por um lado diversas operações implementadas pelo poder público têm como consequência a extensão do processo de gentrificação residencial, efetua-se, por outro lado, a elaboração de políticas que incentivam a contenção desse, sob o plano comercial. Nesse contexto, pode-se verificar uma implicação recente do poder público francês nas dinâmicas comerciais que estruturam e determinam o espaço urbano. A inscrição de atividades comerciais e serviços nos documentos de urbanismo é fruto de diversos diagnósticos e da progressiva identificação do setor imobiliário comercial não somente como bem físico, mas como um agente financeiro. Assim, o mercado imobiliário comercial, que apresenta lógicas distintas daquelas residenciais, representa nos últimos dez anos uma parte importante do capital financeiro dos investidores, atuando como um valor de refúgio em períodos de crise. Em consequência, a dificuldade de controlar esse mercado específico incentivou a implicação do poder público francês no setor.

À luz das dinâmicas assinaladas, diversos instrumentos jurídicos foram desenvolvidos no intuito de mitigar o processo de gentrificação comercial emergente. Ainda que as leis francesas assegurem que uma municipalidade não possa determinar o tipo de atividade comercial a ser instalada em um determinado local, essas podem utilizar-se de mecanismos que incitem o desenvolvimento de um tipo de ocupação almejado. No perímetro de análise examinado anteriormente, o Plan Local d'Urbanisme (PLU) mais recente do arrondissement impõe a preservação de atividades de comércio e de artesanato em algumas vias comerciais assinaladas como significantes para o setor. Tal mecanismo implica que uma atividade comercial local só possa ser substituída por outra de mesmo caráter. 0 exemplo mais singular e polêmico desse cenário se traduz pela instalação de uma loja da sociedade internacional Kieh/s em 2011, que ocupou o espaço de uma antiga flora tradicional. A abertura e funcionamento do novo estabelecimento só foram permitidos sob a condição de acolher concomitantemente um serviço de barbeiros, que incitaria a continuidade 
de uma atividade de caráter artesanal no local. Se por um lado, o cenário é considerado bem-sucedido por alguns, é questionado por outros, que indagam sobre a descaracterização da suposta atividade artesanal e sua real influência na manutenção do comércio local.

Nesse sentido, os instrumentos jurídicos permitem ao poder público de contornar uma dinâmica urbana iminente e de mitigar o processo de gentrificação. Ainda em 2011, uma loja da cadeia alimentar Monoprix, uma das dez maiores cadeias de comércio parisiense, renunciou à sua instalação no setor devido à rigidez regulamentar imposta. Sob essa ótica, as manifestações sociais emergem como importantes agentes para a mitigação da gentrificação comercial. A população atesta, da mesma maneira, investimentos na vida política local, visando a defender a diversidade comercial do setor e a manutenção do comércio tradicional. Como descrito por Sciolino (2012) no New York Times, o fechamento de uma peixaria centenária, a Poissonière Bleue, em 2012 mobilizou diversos comerciantes da Rue des Martyrs. Esse conjunto de profissionais, que detém em sua maioria espaços de comércio tradicionais na via, defendeu a instalação de uma atividade de mesmo caráter no local da antiga peixaria. A mobilização incitou a atenção do prefeito do arrondissement, que garantiu em seu discurso a futura preservação da atividade.

Figura 5 - Implantação conjugada da nova loja da Kiehls

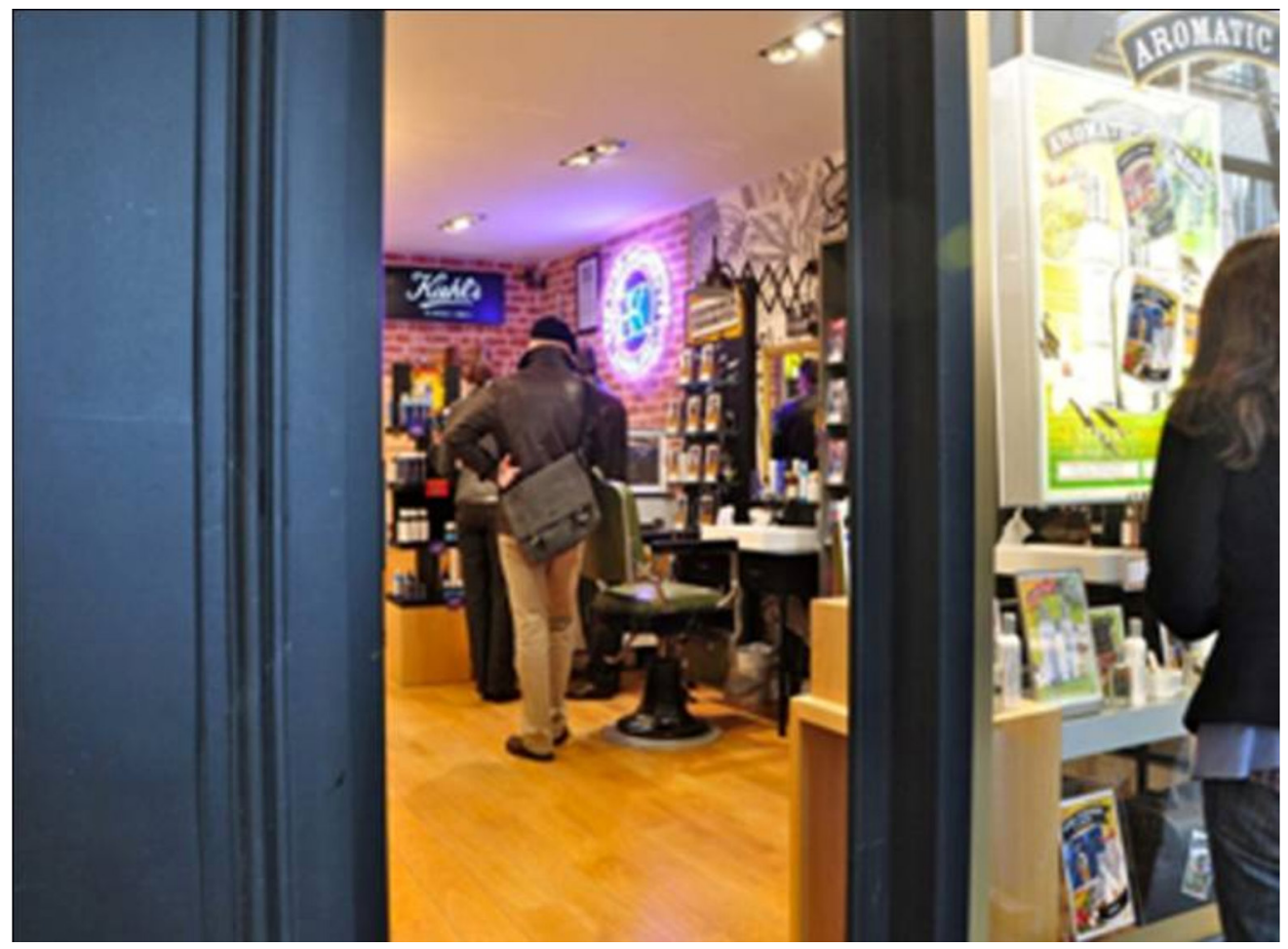

Fonte: Foto de Eugênia Viana Cerqueira (2012). 
Em consonância com o cenário descrito, outros setores parisienses testemunharam a implantação de políticas públicas visando a preservar o comércio local popular, assim como evitar a monofuncionalidade comercial. Um exemplo notável é o setor de Montgallet-Dausmenil, recentemente atingido pela implantação em massa de produtos informáticos. Nesse sentido, a operação Vital'Quartier tem como objetivo favorecer a diversidade comercial e o desenvolvimento de atividades econômicas em setores parisienses pré-diagnosticados. Assim, a prefeitura de Paris delegou à Société d'Economie Mixte d'Aménagement de I'Est de Paris (Semaest) o direito de preempção urbana. Esse instrumento preconiza a compra de locais comerciais vagos pela sociedade em questão e seu posterior aluguel, sob a condição de instalação de uma das atividades almejadas. Dessa maneira, pode-se assegurar a revitalização ou a manutenção de uma identidade comercial popular dos setores identificados como deficientes.

\section{Considerações finais}

A análise tecida permite demonstrar que 0 urbano não constitui apenas uma ciência ou campo de estudo. A dimensão multiescalar abordada permite a articulação entre um panorama global e as peculiaridades da escala local, diretamente integrada à vida cotidiana da população, que habita, experimenta e constitui o espaço urbano. Como postulado por Lefebvre (2003), o fenômeno urbano dialoga com um universo multidisciplinar e com uma realidade global que implica o conjunto da prática social.
Ainda que de maneira irregular, a cidade de Paris foi integralmente submetida aos processos de gentrificação e seus consequentes efeitos nas últimas décadas. No que concerne à dimensão residencial, os vinte arrondissements parisienses centrais testemunham uma valorização progressiva e a consequente expulsão das categorias populares em um movimento centrífugo em direção às áreas periféricas. Por outro lado, a gentrificação comercial se traduz espacialmente de maneira pontual e dispersa. Trata-se, em sua maioria, de antigas vias comerciais que presenciam a metamorfose de sua atividade comercial, passando a abarcar atividades que diferem em natureza e em contexto socioeconômico.

Visando a compreender o impacto do processo de gentrificação comercial sobre a atividade comercial local, procurou-se situar os questionamentos levantados em um típico quartier parisiense que testemunhou a partir da década 90 diversas mutações sociais e urbanas. No caso analisado, tais evoluções configuram, em um curto período, rupturas com uma identidade construída durante mais de um século, uma vez que o processo de gentrificação conduz não somente a uma transformação espacial do território, mas também à reconfiguração das representações urbanas. Assim, sublinha-se uma série de tensões urbanas que não se desenham através de grandes operações urbanas, mas, sim, são traduzidas em escalas pontuais. Em uma escala de análise global, tais transformações seriam pouco visíveis em um primeiro momento, entretanto concernem de maneira singular a relação entre indivíduos e espaço urbano. Consequentemente, o poder público demonstra um investimento gradual nas atividades comerciais e na 
manutenção da cultura popular. Entretanto, as políticas desenvolvidas processam efeitos paradoxais, suscitando ao mesmo tempo a promoção e a contenção da gentrificação. Nesse sentido, os mecanismos elaborados abordam superficialmente um processo cuja abrangência engloba não somente as áreas centrais revalorizadas, mas o espaço urbano como um todo.

As transformações refletidas pelo processo de gentrificação incidem diretamente nas práticas e modelos de representação urbana, assim como no conjunto da organização das sociedades contemporâneas (Mendes, 2011). Sob essa ótica, a análise tecida, incita a questionar a compreensão de novas formas de gentrificação, que emergem não somente como derivadas de ações de renovação urbana direcionadas, mas como frutos da própria esfera urbana como sujeito. Tal cenário desenvolve-se em consonância com os novos paradigmas contemporâneos que promovem novas categorias estruturadas acerca de uma nova geografia de consumo, cultura e lazer. Essas dirigem-se a um contexto de promoção de tais elementos como esfera de mercado e apropriação das classes superiores. Coloca-se, então, em primeiro lugar a imprescindibilidade de compreender a pluralidade das novas hierarquias sociais contemporâneas e os diálogos socioespaciais que tangem às diversas dinâmicas de gentrificação atuais.

\section{Eugênia Dória Viana Cerqueira}

Université Paris 1 Panthéon-Sorbonne, Unité Mixte de Recherche Géographie-Cités. Paris, França. eugeniadoria@gmail.com

\section{Notas}

(1) A cidade de Paris é dividida administrativamente em 20 arrondissements. Cada arrondissement abarca quatro quartiers, unidade administrativa imediatamente inferior. O termo Paris intramuros, atualmente utilizado para designar a conjugação dos 20 arrondissements, ou a cidade centro, refere-se à antiga formação fortificada da aglomeração.

(2) O INSEE (Institut National de la Statistique et des Études Économiques) atualizou em 2003 a classificação categorias socioprofissionais a partir dos seguintes critérios: 1) Agricultores: agricultores de grande e pequeno porte; 2) Artesãos e comerciantes: artesãos, comerciantes e chefes de empresas contendo mais de dez funcionários; 3) Executivos e profissões intermediárias: profissões liberais, executivos da função pública, profissões científicas, engenheiros e técnicos, profissões da informação, administração, artes e espetáculos; 4) Profissões intermediárias: professores de escola, clérigos, técnicos, profissões intermediárias da função pública e empresas; 5) Empregados: empregados civis e agentes da função pública, policiais e militares, empregados de comércio e administrativos; 6) Operários: operários de função industrial, artesanal, manutenção e transporte; 7) Aposentados; 8) Outras pessoas sem atividade profissional: estudantes, desempregados não tendo nunca exercido uma atividade, outros sem atividade profissional. 
(3) Clerval (2005) contesta a caracterização afirmando que as duas categorias em questão constituiriam grupos sociais antagônicos e infusionáveis. Para a autora, o termo é derivado de uma construção da mídia para definir um determinado padrão de consumo. Os chamados bobos seriam, então, principalmente de uma classe média emergente cujos paradigmas estariam articulados a uma nova burguesia.

(4) Bares que abrigam, muitas vezes, atividades relacionadas à prostituição.

(5) Montmartre constitui atualmente um quartier do norte parisiense, cujo nome é derivado da colina homônima. A região é internacionalmente conhecida por ter acolhido diversos artistas no início do século XX e caracterizada como boêmia e local de difusão cultural.

(6) O Direito de Preempção, similar nos casos francês e brasileiro, é um instrumento que confere a uma determinada entidade a preferência na aquisição de um imóvel. No caso explicitado, o direito visa a conferir ao poder público a preferência para adquirir tal bem em consonância com os objetivos das políticas urbanas desenvolvidas.

\section{Referências}

APUR (2011). L'évolution des commerces à Paris - inventaires des commerces 2011 et évolutions 2007-2011. Disponível em: http://www.apur.org/etude/evolution-commerces-paris-inventairecommerces-2011-evolutions-2007-2011. Acesso em: 12 set 2013.

BELL, D. e JAYNE, M. (2004). City of quarters: urban villages in the contemporary city. Aldershot, Ashgate.

BIDOU-ZACHARIASEN, C. (org.). (2006). De volta à cidade: dos processos de gentrificação às políticas de "revitalização" dos centros urbanos. São Paulo, Annablume.

BROOKS, D. (2000). Bobos in Paradise: the new upper class and how they got there. Londres, Simon e Schuster.

CHABROL, B. (2011). De nouvelles formes de gentrification? Dynamiques résidentielles et commerciales dans le quartier de Château-Rouge (Paris). Tese de doutorado. Paris, Universidade de Poitiers.

CLERVAL, A. (2005). Les "Bobos", critique d'un faux concept. Disponível em: http://cybergeo.revues. org/766. Acesso em: 12 set 2013.

(2008). La gentrification à Paris intra-muros: dynamiques spatiales, rapports sociaux et politiques publiques. Tese de doutorado. Paris, Universidade Paris 1 Panthéon-Sorbonne.

(2010). Les dynamiques spatiales de la gentrification à Paris. Disponível em: http://cybergeo. revues.org/23231?lang=en. Acesso em: 7 set 2013.

(2013). Paris sans le peuple. Paris, ISBN.

CLERVAL, A. e FLEURY, A. (2009). Politiques urbaines et gentrification: Une analyse critique à partir du cas de Paris. Disponível em: http://espacepolitique.revues.org/1314. Acesso em: 5 set 2013. 
DIAS, S. (2011). Estratégias recentes de organização urbana comercial - O "SoHo do Porto" e a territorialização de actividades culturais/criativas. Sociologia-Revista da Faculdade de Letras da Universidade do Porto. Porto, n. 21, pp. 69-95.

LEFEVBRE, H. (1999). A revolução urbana. Belo Horizonte, Editora UFMG.

LIPOVETSKY, G. (2006). Le bonheur paradoxal. Paris, Gallimard.

MENDES, L. (2011). Cidade pós-moderna, gentrificação e a produção social do espaço fragmentado. Cadernos Metrópole. São Paulo, v. 13, n. 26, pp. 473-495.

MERMET, C. (2011). Redéfinir la consommation pour repenser les espaces de consommation. Géographie et Cultures, n. 77, pp. 25-44.

POUESSEL, C. (2005). Réinventer les espaces publics par la fête: le cas de Paris. Dissertação de mestrado. Paris, Universidade Paris 1 Panthéon-Sorbonne.

RIBEIRO, R. (2008). Identidade e resistência no urbano: o quarteirão do soul em Belo Horizonte. Tese de doutorado. Belo horizonte, Universidade Federal de Minas Gerais.

SANTOS, M. (2002). A natureza do espaço: técnica e tempo, razão e emoção. São Paulo, Edusp.

SCIOLINO, E. (2012). On a historic street, one that got away. Disponível em: http://www.nytimes. com/2012/11/07/dining/a-historic-street-is-left-with-a-hole.html. Acesso em: 5 set 2013.

SCOTT, A. e LERICHE, F. (2005). Les ressorts géographiques de l'économie culturelle: du local au mondial. L'Espace géographique, n. 34, pp. 207-222.

SEMAEST (2011). Le commerce de proximité dans le Nord Ouest du 9ème arrondissement. Paris, Mairie de Paris.

SMITH, N. (1996). New urban frontier: gentrification and the revanchist city. Londres, Routledge.

(2003). “La gentrification généralisée : d’une anomalie locale à la régénération urbaine comme stratégie urbaine globale". In: BIDOU-ZACHARIASEN, C. (org). Retours en ville : des processus de gentrification urbaine aux politiques de revitalisation des centres. Paris, Descartes et Cie.

SOULIE, M. (1956). Le Quartier Saint-Georges. Tese de doutorado. Paris, Universidade Paris 1-Panthéon Sorbonne.

VAN CRIEKINGEN, M. e FLEURY, A. (2006). La ville branchée: gentrification et dynamiques commerciales à Bruxelles et à Paris. Belgeo, n. 1-2, pp. 113-134.

Texto recebido em 11/out/2013

Texto aprovado em 4/jun/2014 